\title{
Interleukin-6 -174 and -572 Genotypes and the Volume of Deep Gray Matter in Preterm Infants
}

\author{
MILLA REIMAN, RIITTA PARKKOLA, HELENA LAPINLEIMU, LIISA LEHTONEN, LEENA HAATAJA, \\ AND THE PIPARI STUDY GROUP
}

\begin{abstract}
Department of Pediatrics [M.R., H.L., L.L.], Department of Radiology and Turku PET Center [R.P.], Department of Pediatric Neurology [L.H.], Turku University Central Hospital, 20521 Turku, Finland
\end{abstract}

\begin{abstract}
Preterm infants have smaller cerebral and cerebellar volumes at term compared with term born infants. Perinatal factors leading to the reduction in volumes are not well known. IL-6 -174 and -572 genotypes partly regulate individual immunologic responses and have also been connected with deviant neurologic development in preterm infants. Our hypothesis was that IL-6 -174 and -572 genetic polymorphisms are associated with brain lesions and regional brain volumes in very low birth weight or in very preterm infants. DNA was genotyped for IL-6 -174 and -572 polymorphisms (GG/GC/CC). Study infants $(n=175)$ were categorized into three groups according to the most pathologic brain finding in ultrasound examinations until term. The brain MRI performed at term was analyzed for regional brain volumes. Analyzed IL- 6 genotypes did not show statistically significant association with structural brain lesions. However, IL-6 -174 CC and -572 GG genotypes associated with reduced volume of one brain region, the combined volume of basal ganglia and thalami, both in univariate and in multivariate analyses ( $p=0.009,0.009$, respectively). The association of IL-6 -174 and -572 genetic polymorphisms with smaller volumes in deep gray matter provides us new ways to understand the processes leading to neurologic impairments in preterm infants. (Pediatr Res 65: 90-96, 2009)
\end{abstract}

$\mathrm{T}$ he role of cytokines in the process leading to brain lesions of preterm infants has been under intensive research lately. High interleukin (IL)-6 and IL-1 $\beta$ concentrations in amniotic fluid have been found in preterm infants with white matter (WM) lesions (1), and elevated IL-6, IL-8, and IL-1 $\beta$ levels in both umbilical and neonatal blood samples of preterm infants have been found to associate with intracerebral hemorrhage $(2,3)$. Furthermore, in term infants, higher blood levels of IL-6, IL-8, and IL-1 $\beta$ have been reported to associate with abnormal neurodevelopmental outcome at $30 \mathrm{mo}$ of age (4). In contrast, there are studies showing no association between the level of cord serum or neonatal blood proinflammatory cytokines and preterm infant's brain damage $(5,6)$ and neurodevelopmental outcome of preterm infants at $2 \mathrm{y}$ of corrected age (5). Ellison et al. (6) have suggested that plasma cytokine levels may reflect poorly the cerebral inflammatory response in preterm infant, because they found a connection

Received February 4, 2008; accepted August 13, 2008.

Correspondence: Milla Reiman, M.D., Vähä-Hämeenkatu 1 A 6, 20500 Turku, Finland; e-mail: milla.reiman@utu.fi

Supported by grants from The South-Western Finnish Foundation of Neonatal Research, The Foundation for Pediatric Research, The Lea and Arvo Ylppö Foundation and The Päivikki and Sakari Sohlberg Foundation. between high levels of cerebrospinal fluid IL-6, IL-10, and tumor necrosis factor alpha (TNF- $\alpha$ ) and white matter damage (WMD), but no association between plasma cytokines and WMD.

The inflammatory response to infectious stimuli, and thus the clinical outcome of the inflammatory process, is partly regulated by genetic factors. Genetic polymorphism (genotypes $\mathrm{GG} / \mathrm{GC} / \mathrm{CC}$ ) in IL-6 gene promoter -174 and -572 positions affects IL-6 expression. For example, $\mathrm{C}$ allele at the position -572 has been associated with increased IL-6 synthesis $(7,8)$. The effects of IL-6-174 genotypes on the IL-6 response are more controversial. GG genotype at the position -174 has been found to associate with elevated leukocyte (9) and macrophage (10) IL-6 response. On the other hand, CC genotype associated with higher IL-6 production when neonatal monocytes were stimulated with lipopolysaccharide and higher IL-6 production in newborns compared with adults (11).

IL-6 -174 CC genotype has been connected with severe hemorrhagic brain lesions and WMD seen in brain ultrasound (US) in preterm infants (12). In addition, IL-6 -174 CC genotype was associated with disability at 2 or $5 \frac{1}{2}$ y of age (12). Quite contrary, Göpel et al. (13) did not find any association between intraventricular hemorrhage (IVH) and periventricular leukomalacia (PVL) and IL-6 -174 genotypes. In addition, in the only available study of IL-6 -572 polymorphism, IL-6 -572 C genotype was reported to associate with less optimal neurodevelopmental performance at $2 \mathrm{y}$ of corrected age and at $51 / 2 \mathrm{y}$ of age in preterm infants (14). However, there was no association between IL-6 -572 C genotype and IVH or PVL.

Several studies have shown smaller regional cerebral and cerebellar volumes in preterm infants imaged at term compared with term born infants (15-19). For example, preterm infants have been reported to have decreased volumes of the cortical gray matter (17) and deep nuclear gray matter $(15,18,19)$. The risk for reduced brain volumes has been associated with decreasing gestational age $(15,16,19)$ and brain pathology (16,20-22). In preterm infants, a decrease in cerebral gray matter (22) and cortical volume (23) has been associated with poor cognitive performance at school age. In addition, reduction in caudate nuclei (24-26) and thalamus

Abbreviations: IVH, intraventricular hemorrhage; PVL, periventricular leukomalasia; US, ultrasound; WM, white matter; WMD, white matter damage 
volume (27) has been suggested to cause developmental and behavioral problems in preterm infants.

Perinatal factors leading to the reduction in brain volumes in premature infants are not well known. Because proinflammatory cytokines have been suggested to play a role in the development of brain pathology in neonates, it is possible that cytokines also affect the developing brain in more subtle ways causing changes in regional brain growth and maturation potential.

The aim of this study was to test this novel hypothesis of possible association between IL-6 -174 and -572 genotypes and brain volumes. In addition, we evaluated their role on structural brain lesions.

\section{METHODS}

Patient population. This study is a part of a larger multidisciplinary project PIPARI (Development and Functioning of Very Low Birth Weight Infants from Infancy to School Age). The inclusion criteria for the main study were 1) the infant's birth weight $\leq 1500 \mathrm{~g}$ or gestational age below $32 \mathrm{wk}, 2$ ) the infant's parents spoke and understood written Finnish or Swedish, and 3) the families lived inside the hospital catchment area. Nine infants of eligible infants $(n=283)$ were not included in this study because their parents declined to participate. The exclusion criteria were 1) DNA sample was not available and/or 2) brain imaging was not available. Ninety infants of the remaining infants $(n=274)$ were excluded because of missing DNA sample $(n=89)$ or brain imaging $(n=1)$. In multifetal pregnancies, the second and/or third child were excluded from the analyses if the infants had the same gender, had the same blood type, and the both IL-6 genotypes were similar. Altogether nine infants were excluded for these reasons.

The final study population consisted of 175 infants born between January 2001 and December 2006 in the Turku University Central Hospital, Finland. Parental consent was obtained after verbal and written information. This study was approved by the Ethical Committee of the Hospital District of the South-West Finland in June 2001.

The clinical data (Table 1) were collected prospectively as a part of the PIPARI protocol. Gestational age was estimated according to the first- or second-trimester ultrasonography performed routinely in Finland.
IL-6 genotyping. DNA was extracted from the ethylenediaminetetraacetic acid blood samples using the nucleon BACC3-reagent kit (Amersham Biosciences, USA). Analyzed IL-6 promoter regions were amplified using Polymerase Chain Reaction (PCR). The primers were chosen on the basis of previous publications $(7,28)$. PCR was performed in $25 \mu \mathrm{L}$ using $100 \mathrm{ng}$ genomic DNA as a template, $0.4 \mu \mathrm{M}$ of each primer, $80 \mu \mathrm{M}$ dNTP, and $\sim 2$ U DNA polymerase [DynaZyme II/DynaZyme EXT (Finnzymes, FIN) for IL-6 -572 and FastStart Taq (Roche Diagnostics, GE) for IL-6 -174]. PCR included 5-min denaturation at $95^{\circ} \mathrm{C}$ and 35 amplification cycles $(40 \mathrm{~s}$ at $95^{\circ} \mathrm{C}, 30 \mathrm{~s}$ at $60^{\circ} \mathrm{C}$ and $40 \mathrm{~s}$ at $72^{\circ} \mathrm{C}$ for IL- $6-572$ and $1 \mathrm{~min}$ at $95^{\circ} \mathrm{C}, 1 \mathrm{~min}$ at $53^{\circ} \mathrm{C}$, and $1 \mathrm{~min}$ at $72^{\circ} \mathrm{C}$ for IL-6 -174) and final elongation $5 \mathrm{~min}$ at $72^{\circ} \mathrm{C}$. Genotypes were resolved by using restriction fragment length polymorphism (RFLP). The restriction endonucleases used were BsrBI (NEB, US) for IL-6 -572 and NIaIII (NEB, US) for IL-6 -174. Digestion was performed at $37^{\circ} \mathrm{C}$ in $15 \mu \mathrm{L}$ using $6-10 \mu \mathrm{L}$ of PCR product and $3 \mathrm{U}$ of restriction endonuclease for $2 \mathrm{~h}$. The size of the digestion products was determined by using agarose gel electrophoresis.

Serial cranial US examinations. Cranial US examinations in the neonatal intensive care unit were performed for all study infants at 3-5 d, at 7-10 d, at 1 mo of age and, thereafter, monthly until discharge from the hospital by a pediatrician blinded to IL-6 genotypes. The US examinations were performed using a $7 \mathrm{MHz}$ vector transducer (Sonos 5500 Hewlett-Packard, Andover, MA). The classification of IVH (grades I to IV) was performed according to Papile et al. (29). Multiple cysts with typical location in posterior periventricular white matter adjacent to the lateral ventricle and in the WM adjacent to the foramina of Monro were classified as cystic PVL (30).

The cranial US examination at term was performed with $7.5 \mathrm{MHz}$ vector transducer (Aloka SSD 2000, Aloka, Tokyo, Japan) during January 2001August 2002 and $8 \mathrm{MHz}$ vector transducer (General Electric Logic 9) thereafter by a pediatric radiologist blinded to IL- 6 genotypes. Ventriculomegaly was defined according to the reference values for very low birth weight infants at term (Virkola K. The lateral ventricle in early infancy. Doctoral thesis, 1988, Helsinki, Finland).

The infants were categorized into three groups according to the most pathologic finding on brain US examinations: 1) normal, 2) mildly abnormal, and 3) severely abnormal. The division into these groups was performed as described by Rademaker et al. (31).

Magnetic resonance imaging of the brain. A magnetic resonance imaging (MRI) study of the brain was performed at term at the same day as the US examination. The imaging took place during postprandial sleep without pharmacological sedation or anesthesia. Ear protection was used (3M Dis-

Table 1. Characteristics of the study infants $(n=175)$ classified according to the IL-6 genotypes of the infants

\begin{tabular}{|c|c|c|c|}
\hline \multirow[b]{3}{*}{ Characteristics } & \multicolumn{3}{|c|}{ Study infants } \\
\hline & \multirow[b]{2}{*}{ Total, $n=175$} & \multicolumn{2}{|c|}{ IL-6 - $174, n=174$} \\
\hline & & $\mathrm{GG}, n=163$ & GC, $n=11$ \\
\hline Male $n(\%)$ & $102(58)$ & $95(58)$ & $6(55)$ \\
\hline Singleton $n(\%)$ & $129(74)$ & $122(75)$ & $6(55)$ \\
\hline Twin $n(\%)$ & $40(23)$ & $35(21)$ & $5(45)$ \\
\hline Triplet $n(\%)$ & $6(3)$ & $6(4)$ & $0(0)$ \\
\hline Gestational age (wk) & $29^{0 / 7}\left(2^{5 / 7}\right)\left[23^{0 / 7}, 36^{1 / 7}\right]$ & $28^{6 / 7}\left(2^{6 / 7}\right)\left[23^{0 / 7}, 36^{1 / 7}\right]$ & $29^{6 / 7}\left(1^{6 / 7}\right)\left[27^{1 / 7}, 34^{0 / 7}\right]$ \\
\hline Birth weight $(\mathrm{g})$ & $1126(343)[400,2120]$ & $1119(343)[520,2120]$ & $1189(353)[400,1855]$ \\
\hline Birth weight $\mathrm{z}$ score & $-1.36(1.49)[-4.90,3.40]$ & $-1.35(1.47)[-4.70,3.40]$ & $-1.57(1.82)[-4.90,0.60]$ \\
\hline Birth weight $\mathrm{z}$ score $<-2.0 n(\%)$ & $54(31)$ & $50(31)$ & $4(36)$ \\
\hline \multirow[t]{3}{*}{ Apgar score at $5 \mathrm{~min}<5$} & $31(18)$ & $29(18)$ & $2(18)$ \\
\hline & \multicolumn{3}{|c|}{ Study infants } \\
\hline & \multicolumn{3}{|c|}{ IL-6 -174, $n=174$} \\
\hline Characteristics & GG, $n=38$ & $\mathrm{GC}, n=91$ & $\mathrm{CC}, n=45$ \\
\hline Male $n(\%)$ & $24(63)$ & $51(56)$ & $27(60)$ \\
\hline Singleton $n(\%)$ & $33(87)$ & $61(67)$ & $34(76)$ \\
\hline Twin $n(\%)$ & $5(13)$ & $24(26)$ & $11(24)$ \\
\hline Triplet $n(\%)$ & $0(0)$ & $6(7)$ & $0(0)$ \\
\hline Gestational age (wk) & $29^{3 / 7}\left(2^{6 / 7}\right)\left[24^{0 / 7}, 36^{1 / 7}\right]$ & $29^{0 / 7}\left(2^{5 / 7}\right)\left[23^{0 / 7}, 34^{6 / 7}\right]$ & $28^{5 / 7}\left(2^{6 / 7}\right)\left[24^{0 / 7}, 34^{3 / 7}\right]$ \\
\hline Birth weight $(\mathrm{g})$ & $1172(311)[580,1675]$ & $1142(363)[400,2120]$ & $1069(320)[5080,2070]$ \\
\hline Birth weight $\mathrm{z}$ score & $-1.56(1.36)[-4.7,0.7]$ & $-1.29(1.46)[-4.90,2.20]$ & $-1.34(1.68)[-4.40,3.40]$ \\
\hline Birth weight $\mathrm{z}$ score $<-2.0 n(\%)$ & $10(26)$ & $29(32)$ & $15(33)$ \\
\hline Apgar score at $5 \mathrm{~min}<5$ & $7(18)$ & $14(15)$ & $9(20)$ \\
\hline
\end{tabular}

Means (SD) and [min, max] are presented for gestational age, birth weight, and birth weight $\mathrm{z}$ score. 
posable Ear Plugs 1100, 3M, Brazil; Würth Hearing protector, Art.-Nr. 899 300 232, Würth, Austria). The MRI equipment was either an open 0.23 tesla Outlook GP (Philips Medical Vantaa, Finland) (81 infants studied), or 1.5 tesla Philips Intera (Philips Medical Systems, Best, The Netherlands) (91 infants studied). The information about brain lesions in MRI was not used for further analysis as the upgrading of the equipment may result in noncomparable findings between the first and the latter half of the sample.

For volume measurements, at $0.23 \mathrm{~T}$ we obtained T1-weighted field echo (FE) sequence with time repetition (TR) of $30 \mathrm{~ms}$, time echo (TE) of $10 \mathrm{~ms}$, flip angle of 45 degrees, slice thickness of $5 \mathrm{~mm}$, field of view of $220 \times 220$ $\mathrm{mm}^{2}$, and matrix of $256 \times 256$ was obtained in coronal plane. At $1.5 \mathrm{~T}$, we obtained coronal T1-weighted inversion recovery (IR) sequence TR of 3500 $\mathrm{ms}$, TE of $400 \mathrm{~ms}$, time inversion (TI) of $15 \mathrm{~ms}$, flip angle of 90 degrees, slice thickness of $4.8 \mathrm{~mm}$, field of view is $180 \times 180 \mathrm{~mm}^{2}$, and matrix of $256 \times$ 256. The sequences were optimized relative to the field strength of the equipment used.

The postacquisition volume measurements were performed on GE workstation (GE AW1.0, GE Medical Systems, Milwaukee, USA) by one neuroradiologist blinded to IL- 6 genotypes. The coronal T1-weighted images were loaded in the Functool 1.0.postprocessing software (GE Medical Systems, Milwaukee, USA). The volume measurement was manually performed separating cerebrospinal fluid and skull from brain tissue image by image. Anatomical differentiation of the brain areas was based both on the anatomic landmarks and on signal intensity differences of the brain structures. The regional brain volumes measured were cerebral volume, cerebellar volume, frontal lobe volume, the combined volume of the medulla oblongata and the pons, and the combined volume of basal ganglia and thalami. The basal ganglia and thalami were measured as a block and the anatomic border between these basal gray matter nuclei and unmyelinated deep WM on both field strength images was easily delineated by visual inspection. The medial border of the basal ganglia and thalami was formed by the third ventricle, the lateral border was formed by external capsule, and inferior border was formed by the upper border of the mesencephalon.

Statistical analyses. Univariate analysis was performed to determine the relationship between IL-6 -174 and -572 genotypes (GG/GC/CC) and ordinal outcome variable (brain US findings) using cumulative logit models (32). After that, analysis was redone controlling for possible confounding effects of gender, gestational age, and $z$ score of birth weight using cumulative logit models with confounders and genotypes as predictors of severity of US finding.

Diagnostic plots were produced to ensure that assumptions of the analyses were reasonably satisfied. As a result of these checks, inverse transformation was performed to right-skewed distribution of the combined volume of medulla oblongata and pons before data analysis. One-way analysis of variance was conducted to evaluate the effect of IL-6 -174 and -572 genotypes on brain volumes. Analysis of covariance was used to further study the effects of IL-6 -174 and -572 genotypes on brain volumes controlling for possible confounding effects of gender, gestational age, and $z$ score of birth weight.

Statistical analyses were performed using SAS (version 9.1; SAS Institute, Cary, NC). Results are presented with $95 \%$ confidence intervals. Two-sided $p$ values were used with $p<0.05$ being considered statistically significant.

\section{RESULTS}

Of the 175 DNA samples, IL-6 -174 and -572 genotyping was performed successfully to all but one sample in both groups. The prevalence of IL-6 -174 and -572 genotypes (GG/GC/CC) is shown in Table 2. The prevalence of different genotypes did not differ significantly from the Finnish reference population $(33,34)$. The allele frequency follows HardyWeinberg equilibrium. This was tested by using a simulator program http://krunch.med.yale.edu/hwsim/.

The cranial US examinations were performed according to the protocol in intensive care unit to all 175 study infants. At

Table 2. The prevalence of IL-6 -174 and -572 genotypes $(G G / G C / C C)$ in the study population

\begin{tabular}{cccc}
\hline & $\begin{array}{c}\text { GG } \\
\text { genotype, } \\
n(\%)\end{array}$ & $\begin{array}{c}\text { GC } \\
\text { genotype, } \\
n(\%)\end{array}$ & $\begin{array}{c}\text { CC } \\
\text { genotype, } \\
n(\%)\end{array}$ \\
\hline$-174(n=174)$ & $38(22 \%)$ & $91(52 \%)$ & $45(26 \%)$ \\
$-572(n=174)$ & $163(94 \%)$ & $11(6 \%)$ & $0(0 \%)$ \\
\hline
\end{tabular}

term age, all but one infant were examined by the US. The findings in brain US examinations were normal in 55\%, mildly abnormal in $38 \%$, and severely abnormal in $7 \%$ of the study infants. IL-6 -174 and -572 genotypes were not associated with the incidence of mildly or severely abnormal brain lesions in univariate $(-174 p=0.259$, CC versus $\mathrm{GC}$ : $\mathrm{OR}=$ $1.80, \mathrm{CI}=0.88$ to $3.66 ; \mathrm{CC}$ versus $\mathrm{GG}$ : $\mathrm{OR}=1.33, \mathrm{CI}=0.58$ to 3.04 ; $\mathrm{GG}$ versus $\mathrm{GC}$ : $\mathrm{OR}=1.36, \mathrm{CI}=0.65$ to $2.81 ;-572$ GG versus $\mathrm{GC} p=0.870, \mathrm{OR}=1.10, \mathrm{CI}=0.34$ to 3.57 ) nor in multivariate analyses (Table 3). Only gestational age associated significantly with structural brain lesions in US examinations.

Of the 175 study patients, 172 had brain MRI performed at term age. Of these, 153 had regional brain volumes measured and the remaining 19 had qualitatively inadequate images preventing reliable volume measurements. Mean values of the regional brain volumes related to the IL-6 -174 and -572 genotypes are shown in Table 4. IL-6 -174 CC genotype was significantly associated with smaller volume of basal ganglia and thalami both in univariate $(p=0.008, \mathrm{CC}$ versus $\mathrm{GC}$ : estimated difference between means $=-1.77, \mathrm{CI}=-3.82$ to 0.27; CC versus GG: estimated difference between means = $-3.19, \mathrm{CI}=-5.61$ to -0.78 ; $\mathrm{GC}$ versus $\mathrm{GG}$ : estimated difference between means $=-1.42, \mathrm{CI}=-3.47$ to 0.63 ) and in multivariate analyses (Table 5). IL-6 -572 GG genotype was also significantly associated with smaller volume of basal ganglia and thalami both in univariate (GG versus $\mathrm{GC}: p=$ 0.008 , estimated difference between means $=-3.86, \mathrm{CI}=$ -6.72 to -1.00 ) and in multivariate analyses (Table 5). In addition, smaller gestational age and smaller $z$ score of birth weight were significantly associated with reduction in basal ganglia and thalami volume. IL-6-174 and -572 genotypes had no significant associations with the other regional brain volumes measured.

\section{DISCUSSION}

To our knowledge, this is the first study to examine the association between IL-6 -174 and -572 genotypes and re-

Table 3. The multivariate analyses of the associations between IL-6 -174 and -572 genotypes (GG/GC/CC) and the brain lesions in the ultrasound examinations adjusted for gender, gestational age, and $z$ score of birth weight $(n=175)$

\begin{tabular}{|c|c|c|}
\hline & OR ( $95 \%$ confidence intervals) & $p$ \\
\hline IL-6 -174 & & 0.359 \\
\hline CC vs. GC & $1.68(0.80$ to 3.53$)$ & 0.171 \\
\hline CC vs. GG & $1.20(0.51$ to 2.87$)$ & 0.675 \\
\hline GG vs. GC & $1.40(0.65$ to 2.99$)$ & 0.392 \\
\hline Male gender & $1.38(0.72$ to 2.58$)$ & 0.318 \\
\hline $\begin{array}{l}\text { Gestational age (per } 1 \mathrm{~d} \\
\text { decrease) }\end{array}$ & 1.04 (1.02 to 1.06$)$ & $<0.0001$ \\
\hline $\begin{array}{l}z \text { Score of birth weight (per } \\
\text { one unit decrease) }\end{array}$ & $1.26(1.00$ to 1.60$)$ & 0.054 \\
\hline \multicolumn{3}{|l|}{ IL-6 -572 } \\
\hline GG vs. GC & $0.82(0.24$ to 2.82$)$ & 0.750 \\
\hline Male gender & $1.42(0.76$ to 2.65$)$ & 0.274 \\
\hline $\begin{array}{l}\text { Gestational age (per } 1 \mathrm{~d} \\
\text { decrease) }\end{array}$ & 1.04 (1.02 to 1.06$)$ & $<0.0001$ \\
\hline $\begin{array}{l}z \text { Score of birth weight (per } \\
\text { one unit decrease) }\end{array}$ & $1.27(1.00$ to 1.61$)$ & 0.047 \\
\hline
\end{tabular}


Table 4. Mean values $(m L)$ and $[S D]$ of the regional brain volumes related to the IL-6 -174 and -572 genotypes (GG/GC/CC) in the study population $(n=153)$

\begin{tabular}{|c|c|c|c|c|c|}
\hline & Cerebrum & Cerebellum & Frontal lobe & $\begin{array}{l}\text { Medulla oblongata and } \\
\text { pons together }\end{array}$ & $\begin{array}{l}\text { Basal ganglia and } \\
\text { thalami together }\end{array}$ \\
\hline \multicolumn{6}{|l|}{ IL-6 -174 } \\
\hline $\mathrm{CC}, n=36$ & $361.6[46.4]$ & $23.4[3.3]$ & $123.2[21.6]$ & $5.6[2.0]$ & 23.5 [3.9] \\
\hline $\mathrm{GC}, n=81$ & $372.2[48.5]$ & $24.0[5.9]$ & $126.6[25.5]$ & $6.0[2.4]$ & $25.2[4.0]$ \\
\hline $\mathrm{GG}, n=36$ & $375.1[46.0]$ & $25.8[4.9]$ & $130.5[25.5]$ & $6.5[2.4]$ & $26.7[5.3]$ \\
\hline \multicolumn{6}{|l|}{ IL-6 -572 } \\
\hline GG, $n=143$ & $368.4[46.8]$ & $24.0[5.3]$ & $125.4[24.4]$ & $5.9[2.1]$ & $24.8[4.1]$ \\
\hline $\mathrm{GC}, n=10$ & $380.8[62.8]$ & $26.2[5.0]$ & $140.2[29.2]$ & $7.6[4.5]$ & $28.7[7.5]$ \\
\hline
\end{tabular}

gional brain volumes. In our study, both IL-6 -174 CC and -572 GG genotypes associated with smaller combined volume of basal ganglia and thalami, but there was no association to structural brain lesions of preterm infants.

Several factors can affect the cytokine concentrations in blood and in amniotic fluid, delivery being one of them (11), which makes it difficult to interpret the associations reported between cytokine levels and brain lesions (1-3). In addition, it has been suggested that plasma cytokine levels may reflect poorly the cerebral inflammatory response in preterm infants (6). Genetic polymorphism of cytokine promoter regions modulates cytokine production, and therefore analysis of known functionally relevant genotypes eliminates the effects of external confounding factors.

IL-6 -174 and -572 genotypes have been connected with deviant neurologic development $(12,14)$. These findings suggest that genetically determined individual capacity to regulate inflammatory responses does effect the developing brain in preterm infants. It has recently been reported that IL-6-type cytokines also act as factors influencing the development of neurons and glial cells in the central nervous system in addition to their role in inflammatory processes (35-37). These reports provide us a potential theoretical background to our study results. Because different genotypes of IL-6 promoter region affect inflammatory cytokine production, it is plausible that polymorphisms also act functionally in neural development.

Basal ganglia and thalamus are particularly vulnerable to e.g. hypoxic-ischemic insults during development (38). A fetal insult during thalamic neurogenesis in the nonhuman primates has also been shown to produce thalamic volume loss and shape deformation in adulthood (39). Injury to this particular area may present itself as a problem in a wide range of functions, including control of movement, cognition, emotion, and behavior. It is known that basal ganglia injury can lead to cerebral palsy (CP) both in preterm $(40,41)$ and in term infants $(40,42)$. In addition, hyperechogenity in basal ganglia and thalamus has been associated with neurodevelopmental delay, particularly cognitive and behavioral problems, in preterm infants (43).

Three recent reports have shown that preterm infants at term age have reduced deep gray matter volumes $(15,18,19)$. Inder et al. (15) used an automated tissue segmentation method to define cerebral tissue types, and demonstrated marked reduction in cortical and deep nuclear gray matter volume. The main predictors of volume reduction were ges- tational age at birth and the presence of WM injury. Boardman et al. (19), using deformation-based morphometry, identified deep gray matter growth failure associated with diffuse WM injury (defined as increased apparent diffusion coefficient, ADC, values). They suggested that growth failure is not an isolated phenomenon, but might be associated with disconnection of the thalamus from the developing cortex. The connection of WM injury and reduced deep gray matter volumes was confirmed by Srinivasan et al. (18). They showed, using manual volumetry and a 3-tesla MRI system, that volume reduction was most marked among infants with such supratentorial lesions as IVH, PVL, and hemorrhagic parenchymal infarction, but was also evident in infants with mild and moderate WM abnormalities. Even though the results of these studies $(15,18,19)$ support each other, different MRI-analysis techniques make their comparison difficult. Boardman et al. (19) suggested that either injury to the preoligodendrocyte or axon might cause disconnection between cortex and thalamus, and thus abnormal neuronal differentiation and organization (44). As an alternative mechanism, both Boardman et al. (19) and Srinivasan et al. (18) proposed that damage to the transient cortical subplate might also lead to thalamocortical decoupling, as subplate is required to control early thalamocortical tract development (45). In the light of our results with the decreased volume of deep gray matter, and the recent reports of IL-6-type cytokines influencing the development of neurons and glial cells (35-37), one can speculate that IL-6 may have a role in the complex process of guiding and sustaining neural tract development.

A potential limitation to our study is the upgrading of the MRI equipment during the data collection period. This might affect the image contrast, and thus the ability to differentiate adjacent anatomic structures. To avoid this, we selected easily definable anatomic landmarks, which are not affected by contrast changes in MRI. According to the recent reports $(15,18,19,46)$, it is likely that also in our study the reductions in deep gray matter are at least partly caused by WM injuries. Because our aim was to explore the association between genetic polymorphism and overt brain pathology, our research methodology did not allow us to analyze reliably the association between detailed WM abnormalities and deep gray matter volume. Another limitation is a relatively small study population: only 11 (6\%) infants had IL-6-572 GC and none had CC genotype as consistent with Finnish population. The low prevalence of IL-6-572 GC genotype reduces the power of the study to detect other associations. Adjustments for 
REIMAN $E T A L$.

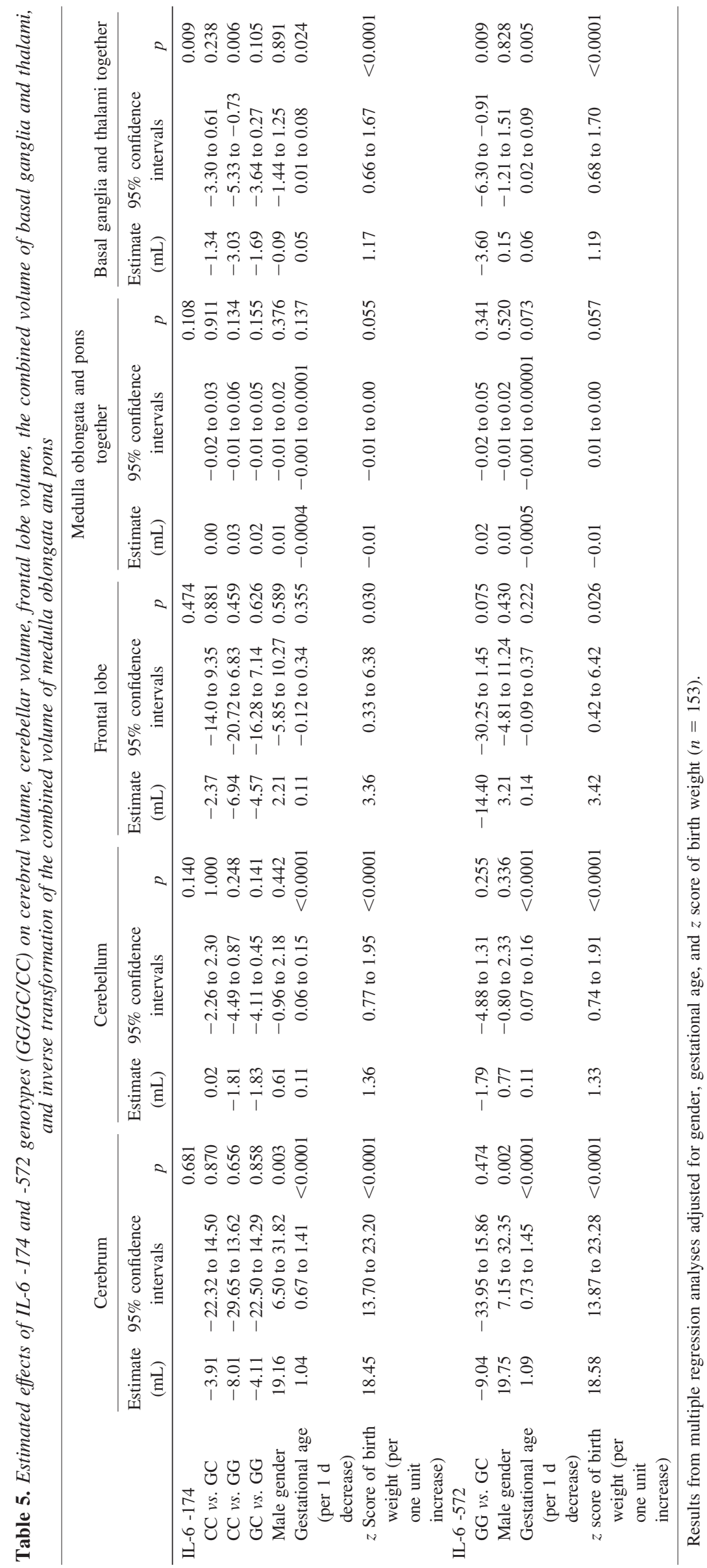


multiple comparisons would increase the probability of a type 1 error (error of rejecting a null hypothesis when it is actually true) at the expense of a type 2 error (failure to reject a false hypothesis). Therefore, no adjustments for multiple comparisons were made, but we acknowledge that this could lead to incidental findings.

In conclusion, our study shows that IL-6 -174 CC and -572 GG genotypes may be associated with reduced volumes in deep gray matter in very low birth weight or very preterm infants. The finding provides us new ways to understand the processes leading to neurologic impairments in preterm infants.

Acknowledgments. The PIPARI Study Group includes Satu Ekblad, R.N., Eeva Ekholm, M.D., Ph.D., Leena Haataja, M.D., Ph.D., Pentti Kero, M.D., Ph.D., Riikka Korja, MSc, Harry Kujari, M.D., Helena Lapinleimu M.D., Ph.D., Liisa Lehtonen, M.D., Ph.D., Hanna Manninen, M.D., Jaakko Matomäki, MSc, Jonna Maunu, M.D., Petriina Munck, M.A., Pekka Niemi, Ph.D., Pertti Palo, M.D., Ph.D., Riitta Parkkola, M.D., Ph.D., Jorma Piha, M.D., Ph.D., Annika Lind, M.A., Liisi Rautava, M.D., Päivi Rautava, M.D., Ph.D., Milla Reiman, M.D., Hellevi Rikalainen, M.D., Katriina Saarinen, Physiotherapist, Elina Savonlahti, M.D., Matti Sillanpää, M.D., Ph.D., Suvi Stolt, Phil. Lic, Päivi Tuomikoski-Koiranen, R.N., Tuula Äärimaa, M.D., Ph.D.

We thank Kirsi Huoponen, Ph.D. and Kukka Aimonen at Department of Genetics in Turku University for performing the genetic analysis.

\section{REFERENCES}

1. Yoon BH, Jun JK, Romero R, Park KH, Gomez R, Choi JH, Kim IO 1997 Amniotic fluid inflammatory cytokines (interleukin-6, interleukin-1 beta, and tumor necrosis factor-alpha), neonatal brain white matter lesions, and cerebral palsy. Am J Obstet Gynecol 177:19-26

2. Tauscher MK, Berg D, Brockmann M, Seidenspinner S, Speer CP, Groneck P 2003 Association of histologic chorioamnionitis, increased levels of cord blood cytokines, and intracerebral hemorrhage in preterm neonates. Biol Neonate 83:166-170

3. Heep A, Behrendt D, Nitsch P, Fimmers R, Bartmann P, Dembinski J 2003 Increased serum levels of interleukin 6 are associated with severe intraventricular haemorrhage in extremely premature infants. Arch Dis Child Fetal Neonatal Ed 88:F501-F504

4. Bartha AI, Foster-Barber A, Miller SP, Vigneron DB, Glidden DV, Barkovich AJ, Ferriero DM 2004 Neonatal encephalopathy: association of cytokines with MR spectroscopy and outcome. Pediatr Res 56:960-966

5. Kaukola T, Herva R, Perhomaa M, Päkkö E, Kingsmore S, Vainionpää L, Hallman M 2006 Population cohort associating chorioamnionitis, cord inflammatory cytokines and neurologic outcome in very preterm, extremely low birth weight infants. Pediatr Res 59:478-483

6. Ellison VJ, Mocatta TJ, Winterbourn CC, Darlow BA, Volpe JJ, Inder TE 2005 The telationship of CSF and plasma cytokine levels to cerebral white matter injury in the premature newborn. Pediatr Res 57:282-286

7. Brull DJ, Montgomery HE, Sanders J, Dhamrait S, Luong L, Rumley A, Lowe GD, Humphries SE 2001 Interleukin-6 gene $-174 \mathrm{G}>\mathrm{C}$ and $-572 \mathrm{G}>\mathrm{C}$ promoter polymorphisms are strong predictors of plasma interleukin- 6 levels after coronary artery bypass surgery. Arterioscler Thromb Vasc Biol 21:1458-1463

8. Mälarstig A, Wallentin L, Siegbahn A 2007 Genetic variation in the interleukin-6 gene in relation to risk and outcomes in acute coronary syndrome. Thromb Res 119:467-473

9. Rivera-Chavez FA, Peters-Hybki DL, Barber RC, O'Keefe GE 2003 Interleukin-6 promoter haplotypes and interleukin-6 cytokine responses. Shock 20:218-223

10. Castellucci L, Menezes E, Oliveira J, Magalhaes A, Guimaraes LH, Lessa M, Ribeiro S, Reale J, Noronha EF, Wilson ME, Duggal B, Beaty TH, Jeronimo S, Jamieson SE, Bales A, Blackwell JM, de Jesus AR, Carvalho EM 2006 Il-6-174 G/C promoter polymorphism influences susceptibility to mucosal but not localized cutaneous leishmaniasis in brazil. J Infect Dis 194:519-527

11. Kilpinen S, Hulkkonen J, Wang XY, Hurme M 2001 The promoter polymorphism of the interleukin- 6 gene regulates interleukin- 6 production in neonates but not in adults. Eur Cytokine Netw 12:62-68
12. Harding DR, Dhamrait S, Whitelaw A, Humphries SE, Marlow N, Montgomery HE 2004 Does interleukin-6 genotype influence cerebral injury or developmental progress after preterm birth? Pediatrics 114:941-947

13. Göpel W, Härtel C, Ahrens P, König I, Kattner E, Kuhls E, Küster H, Möller J, Müller D, Roth B, Segerer H, Wieg C, Herting E 2006 Interleukin-6-174-genotype, sepsis and cerebral injury in very low birth weight infants. Genes Immun 7:65-68

14. Harding D, Brull D, Humphries E, Whitelaw A, Montgomery H, Marlow N 2005 Variation in the interleukin-6 gene is associated with impaired cognitive development in children born prematurely: a preliminary study. Pediatr Res 58:117-120

15. Inder TE, Warfield SK, Wang H, Hüppi PS, Volpe JJ 2005 Abnormal cerebral structure is present at term in premature infants. Pediatrics 115:286-294

16. Limperopoulos C, Soul JS, Gauvreau K, Huppi PS, Warfield SK, Bassan H, Robertson RL, Volpe JJ, du Plessis AJ 2005 Late gestation cerebellar growth is rapid and impeded by premature birth. Pediatrics 115:688-695

17. Peterson BS, Anderson AW, Ehrenkranz R, Staib LH, Tageldin M, Colson E, Gore JC, Duncan CC, Makuch R, Ment LR 2003 Regional brain volumes and their later neurodevelopmental correlates in term and preterm infants Pediatrics 111:939-948

18. Srinivasan L, Dutta R, Counsell SJ, Allsop JM, Boardman JP, Rutherford MA, Edwards AD 2007 Quantification of deep gray matter in preterm infants at termequivalent age using manual volumetry of 3-Tesla magnetic resonance images. Pediatrics 119:759-765

19. Boardman JP, Counsell SJ, Rueckert D, Kapellou O, Bhatia KK, Aljabar P, Hajnal J, Allsop JM, Rutherford MA, Edwards AD 2006 Abnormal deep grey matter development following preterm birth detected using deformation-based morphometry. Neuroimage 32:70-78

20. Vasileiadis GT, Gelman N, Han VK, Williams LA, Mann R, Bureau Y, Thompson RT 2004 Uncomplicated intraventricular hemorrhage is followed by reduced cortical volume at near-term age. Pediatrics 114:e367-e372

21. Inder TE, Huppi PS, Warfiel S, Kikinis R, Zientara GP, Barnes PD, Jolesz F, Volpe JJ 1999 Periventricular white matter injury in the premature infant is followed by reduced cerebral cortical grey matter volume at term. Ann Neurol 46:755-760

22. Reiss AL, Kesler SR, Vohr B, Duncan CC, Katz KH, Pajot S, Schneider KC, Makuch RW, Ment LR 2004 Sex differences in cerebral volumes of 8-year-olds born preterm. J Pediatr 145:242-249

23. Peterson BS, Vohr B, Staib LH, Cannistraci CJ, Dolberg A, Schneider KC, Katz KH, Westerveld M, Sparrow S, Anderson AW, Duncan CC, Makuch RW, Gore JC, Ment LR 2000 Regional brain volume abnormalities and long-term cognitive outcome in preterm infants. JAMA 284:1939-1947

24. Abernethy LJ, Cooke RW, Foulder-Hughes L 2004 Caudate and hippocampal volumes, intelligence, and motor impairment in 7-year-old children born preterm. Pediatr Res 55:884-893

25. Abernethy LJ, Palaniappan N, Cooke RW 2002 Quantitative magnetic resonance imaging of the brain in survivors of very low birth weight. Arch Dis Child $87: 279-283$

26. Nosarti C, Allin MP, Frangou S, Rifkin L, Murray RM 2005 Hyperactivity in adolescents born very preterm in associated with decreased caudate volume. Biol Psychiatry 57:661-666

27. Gimenez M, Junque C, Narberhaus A, Botet F, Bargallo N, Mercader JM 2006 Correlations of thalamic reductions with verbal fluency impairment in those born prematurely. Neuroreport 17:463-466

28. Fishman D, Faulds G, Jeffery R, Mohamed-Ali V, Yudkin JS, Humphries S, Woo P 1998 The effect of novel polymorphism in the interleukin-6 (IL-6) gene on IL-6 transcription and plasma IL-6 levels, and an association with systemic onset juvenile chronic arthritis. J Clin Invest 102:1369-1376

29. Papile L-A, Burstein J, Burstein R, Koffler H 1978 Incidence and evolution of subependymal 18 and intraventricular hemorrhage: a study of infants with birth weight less than $1500 \mathrm{gm}$. J Pediatr 92:529-534

30. Barkovich AJ 1995 Pediatric Neuroimaging. New York: Raven Press. pp 120-128

31. Rademaker KJ, Uiterwaal CS, Beek FJ, van Haastert IC, Lieftink AF, Groenendaal F, Grobbee DE, de Vries LS 2005 Neonatal cranial ultrasound versus MRI and neurodevelopmental outcome at school age in children born preterm. Arch Dis Child Fetal Neonatal Ed 90:F489-F493

32. Allison P 1999 Logistic Regression using SAS: Theory and Applications. NC:SAS Institute Inc. pp 133-148

33. Noponen-Hietala N, Virtanen I, Karttunen R, Schwenke S, Jakkula E, Li H, Merikivi R, Barral S, Ott J, Karppinen J, Ala-Kokko L 2005 Genetic variations in IL6 associate with intervertebral disc disease characterized by sciatica. Pain 114:186194

34. Hulkkonen J, Pertovaara M, Antonen J, Pasternack A, Hurme M 2001 Elevated interleukin-6 plasma levels are regulated by the promoter region polymorphism of the IL6 gene in primary Sjögrens syndrome and correlate with the clinical manifestations of the disease. Rheumatology 40:656-661

35. Koch M, May U, Kuhns S, Drechsler H, Adam N, Hattermann K, Wirtz S, Rose-John S, Scheller J 2007 Interleukin 27 induces differentiation of neural C6-precursor cells into astrocytes. Biochem Biophys Res Commun 364: 483-487

36. Taga T, Fukuda S 2005 Role of IL-6 in the neural stem cell differentiation. Clin Rev Allergy Immunol 28:249-256

37. Nakanishi M, Niidome T, Matsuda S, Akaike A, Kihara T, Sugimoto H 2007 Microglia-derived interleukin-6 and leukaemia inhibitory factor promote astrocytic differentiation of neural stem/progenitor cells. Eur J Neurosci 25:649-658

38. Cowan F, Ruthenford M, Groenendaal F, Eken P, Mercuri E, Bydder GM 2003 Origin and timing of brain lesions in term infants with neonatal encephalopathy. Lancet 361:736-742 
39. Schindler MK, Wang L, Selemon LD, Goldman-Rakic PS, Rakic P, Csernansky JG 2002 Abnormalities of thalamic volume and shape detected in fetally irradiated rhesus monkeys with high dimension brain mapping. Biol Psychiatry 51:827-837

40. Bax M, Tydeman C, Flodmark O 2006 Clinical and MRI correlates of cerebral palsy: the european cerebral palsy study. JAMA 296:1602-1608

41. Krägeloh-Mann I, Petersen D, Hagberg G, Vollmer B, Hagberg B, Michaelis R 1995 Bilateral spastic cerebral palsy - MRI pathology and origin. Analysis from a representative series of 56 cases. Dev Med Child Neurol 37:379-397

42. Krägeloh-Mann I, Helber A, Mader I, Staudt M, Wolff M, Groenendaal F, de Vries L 2002 Bilateral lesions of thalamus and basal ganglia: origin and outcome. Dev Med Child Neurol 44:477-484
43. Chamnanvanakij S, Rogers CG, Luppino C, Broyles SR, Hickman J, Perlman JM 2000 Linear hyperechogenicity within basal ganglia and thalamus of preterm infants. Pediatr Neurol 23:129-133

44. Marin-Padilla M 1999 Developmental neuropathology and impact of perinatal brain damage. III gray matter lesions of the neocortex. J Neuropathol Exp Neurol 58:407-429

45. Kostovic I, Judaš M, Radoš M, Hrabač P 2002 Laminar organization of the human fetal cerebrum revealed by histochemical markers and magnetic resonance imaging. Cereb Cortex 12:536-544

46. Pierson CR, Folkerth R, Billiards SS, Trachtenberg FL, Drinkwater ME, Volpe JJ, Kinney HC 2007 Gray matter injury associated with periventricular leukomalacia in the premature infant. Acta Neuropathol 114:619-631 